\title{
The Innovation and Practice of Way of Innovative and Entrepreneurial Talent Cultivation based on the Internet Plus
}

\author{
Wan-xin XUE, and Yi-lei PEl ${ }^{2, b,{ }^{*}}$ \\ ${ }^{1,2}$ Management College, Beijing Union University, Beijing, China \\ axuewanxin@126.com, ${ }^{b}$ peiyilei@126.com
}

Keywords: Internet Plus, Innovation, Talent cultivation, Innovation way.

\begin{abstract}
E-commerce specialty of Management College in Beijing Union University, explores the innovation of ways to cultivate innovative and entrepreneurial talents with innovative thinking and entrepreneurial spirit, relying on the modern service industry, the demonstrative innovation practice base in Beijing higher school, Hive entrepreneurial space, based on the background of Internet Plus, mass entrepreneurship and innovation, and conducts the effective research and practice to cultivate innovative and entrepreneurial talents.
\end{abstract}

\section{Introduction}

Our country is in the Internet Plus era, Premier Li Keqiang put forward the the goal of mass entrepreneurship and innovation. E-commerce specialty is facing new opportunities and challenges, as the specialty integrating with the culture, economy, information and related industries. E-commerce specialty of Management College in Beijing Union University, meets the needs of the development of the times actively, relies on the modern service industry, the demonstrative innovation practice base in Beijing higher school and Hive entrepreneurial space, uses various professional brand events, carries out the education and teaching reform and practice of E-commerce specialty under the new situation, explores the innovation of ways to cultivate innovative and entrepreneurial talents with innovative thinking and entrepreneurial spirit, and conducts the effective research and practice to cultivate innovative and entrepreneurial talents.

\section{The Innovation of Ways to Cultivate Innovative and Entrepreneurial Talents}

Using the Method of Comparative Research, and Establishing the Idea of Innovative and Entrepreneurial Talent Cultivation for Promoting the Training, Learning and Entrepreneurship through the Competition

The paper puts forward the idea of talent cultivation for promoting the training through the competition, promoting the learning through the competition, and promoting the entrepreneurship through the competition, through the comparative analysis of innovative and entrepreneurial abilities various events require, such as National College Student "Innovation, Originality and Entrepreneurship" Challenge, the Ministry of Education, China Students Service Outsourcing Innovation \& Entrepreneurship Competition, National Students' Network Business Innovation Application Competition, and China College Student' Entrepreneurship Competition. 


\section{Using System Research Methods and Forming Innovative Ways to Cultivate Talents}

Rely on events, clear the idea, set up the platform, use the right approach, and achieve the desired goal ultimately. Details are shown in figure 1.

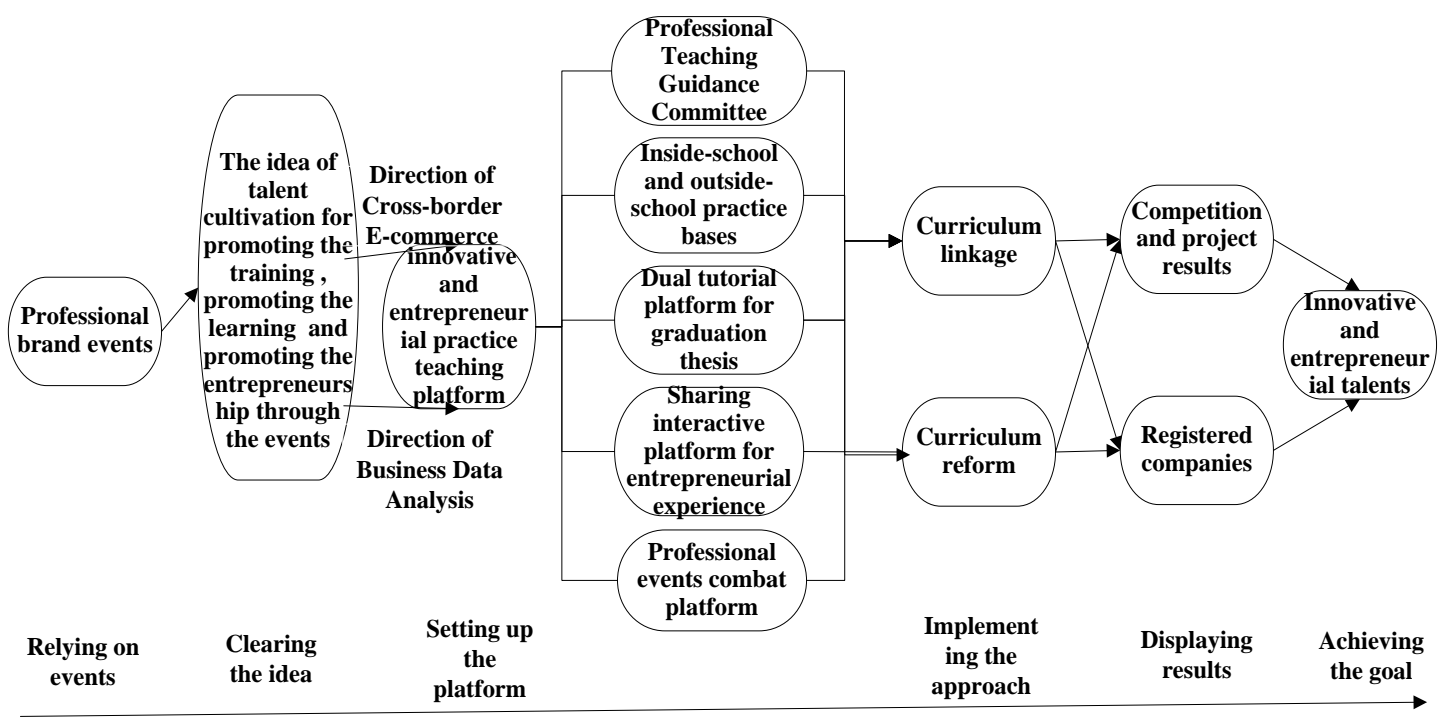

Figure 1. The innovative ways to cultivate innovative and entrepreneurial talents

Building Innovative and Entrepreneurial Practice Teaching Platform based on the Idea of Innovative and Entrepreneurial Talent Cultivation for Promoting the Training, Learning and Entrepreneurship through the Competition

Build innovative and entrepreneurial practice teaching platform, under the guidance of the concept of idea for talent cultivation of innovative and entrepreneurial talent cultivation for promoting the training through the events, promoting the learning through the events, and promoting the entrepreneurship through the events. Innovative practice teaching platform is composed of professional teaching guidance committee, professional inside-school and outside-school practice bases, dual tutorial platform for graduation thesis between college and enterprise, sharing interactive platform for entrepreneurial experience between entrepreneurs and college students, innovative and entrepreneurial practice platform.

\section{Carrying out the Curriculum Linkage and Curriculum Reform, based on Innovative Practice Teaching Platform}

By event linkage, project driving and curriculum integration, try to integrate all kinds of internal and external quality resources and curriculum, decompose the ability based on competition projects, enterprise projects and entrepreneurial actual projects, and complete ability cultivation in the curriculum according to modules. Make full use of the information resources, such as network class in each course, invite the enterprise staff with more experience to come into the classroom. 12 enterprise experts in total take part in E-commerce professional practice and expand teaching contents. Design and implement teaching contents hierarchically.

Draw on the experience of foreign university's assessment methods; increase the process assessment, such as group assignment, students' presentation, investigation report, make evaluation standards of e-commerce talent cultivation; implement the dual tutorial system, assessment method of students' enterprise practice credit, incentives 
management method of academic competitions students participate in; and establish guarantee mechanism that enterprise instructors walk into the classroom.

Study on the individual needs of students, set up students' innovation and entrepreneurship courses such as "self management and innovation"; use "Introduction to E-commerce" platform course experiments, guide students to carry out online entrepreneurship-Taobao shop operating, according to needs. Students have opened more than 500 shops.

\section{Improving Guarantee and Evaluation Mechanism of Talent Cultivation through the Combination of Target Evaluation and Process Evaluation}

Draw on the experience of foreign university's assessment methods, introduce the process assessment, such as enterprise evaluation of projects, students' presentation, market investigation report, and thesis oral defense, make evaluation standards of innovative and entrepreneurial talent cultivation; implement assessment method of students' enterprise practice credit and innovative and entrepreneurial credit, incentives management method of academic competitions students participate in; and establish guarantee mechanism that enterprise instructors enter into the classroom and professional tutors enter into the enterprise.

\section{The Practice of Innovative and Entrepreneurial Talent Cultivation based on Internet Plus}

\section{Establishing the Idea of Innovative and Entrepreneurial Talent Cultivation through Brand Events}

With the help of various professional brand events, conduct courses linkage, industry, universities and enterprises expert linkage; form the idea of talent cultivation for promoting the training through the events, promoting the learning through the events, and promoting the entrepreneurship through the events, and clear the way of innovative and entrepreneurial talent cultivation based on Internet plus.

\section{Expanding Professional Direction based on Social Needs of the Cultivation of Innovative and Entrepreneurial Ability}

Based on social needs of the cultivation of innovative and entrepreneurial ability, the research has gone through 2-year investigation of a large number of enterprises and universities. Through comparative study of cross-border e-commerce talent standards and cultivation model of universities, associations and enterprises, such as the German and British Universities, Heilongjiang University, Nanjing University of Science and Technology, Nanjing Agricultural University, the Northeastern University at Qinhuangdao, Qingdao Cross-border E-commerce Association, Tianjin Enterprise Information \& E-commerce Association and Ruston Express, determine the directions of business data analysis and cross-border e-commerce. 32 students have entered into business data analysis direction for study; the investigation among universities at home and abroad, enterprises and associations has been completed for cross-border e-commerce direction, the draft of cultivation program and the teaching staff cultivation have been completed.

\section{Building Innovative and Entrepreneurial Practice Teaching Platform}

Set up professional teaching guidance committee. 5 experts are from e-commerce professional teaching guidance committee, the Ministry of education; 3 experts are 
from well-known Internet companies such as Tencent; and 10 experts are from E-Commerce Industry Association.

Set up the professional inside-school and outside-school practice base. The base is composed of inside-school mobile E-commerce laboratory, modern service industry -the Demonstrative Innovation Practice Base in Beijing higher school, Beijing Union University Economic and Trade Experimental Teaching Center, Beijing City Experimental Teaching Demonstration Center, Shanghai Shopex Co. Ltd., Neusoft Education Co. Ltd, Beijing Jinxiang Online Science and Technology Co. Ltd., Beijing Justep Science and Technology Co., Ltd. Beyondsoft Co., Ltd, Beijing Yuyan Zhixiang Science and Technology Co. Ltd., Beijing City Software Testing Center, Xinwanghulian company, and China Internet association. In 2010, E-commerce specialty established school-level outside-school practice teaching base for cultivating talents with Beijing Jinxiang Online Science and Technology Co. Ltd.. E-commerce specialty established school-level inside-school and outside-school practice teaching base with Neusoft Education Co. Ltd., and it was approved as school-level outside-school base for cultivating talents. E-commerce specialty also signed a new agreement with Beijing Justep Science and Technology Co., Ltd.. Since 2014, E-commerce specialty has organized 201 students for Dalian Neusoft University of Information and Shenyang Neusoft Education to learn advanced technology and experience professional training. Assign more than 60 students to the new network company, Beijing City Software Testing Center, Jinxiang Online Science and Technology Co. Ltd. for summer practice, so as to expand the space for cultivating students' comprehensive ability. Send 22 professional teachers to enterprises for the practice.

Set up dual tutorial platform for graduation thesis (design) between university and enterprise. In the specialty of economics and management, implement dual tutorial system for graduation thesis first. Hire industry and enterprise experts as enterprise mentors for the session of 2014, 2015 and 2016 students. For nearly 3 years, a total of 9 students have obtained the title of school-level excellent graduation thesis (design).

Set up sharing interactive platform for entrepreneurial experience between entrepreneurs and university students. Continuously hold 5 E-commerce innovation and entrepreneurship forums, hire 17 entrepreneurs to enter into the campus, and interact with the students for topics of Internet thinking, entrepreneurial process sharing and business management on site.

Set up actual professional events combat platform. Provide students with professional event combat platform. Host the 6th National College Student "Innovation, Originality and Entrepreneurship" Challenge Final in Beijing, the Ministry of Education; Organize the 1st Internet Plus Innovation and Entrepreneurship Competition, Service Outsourcing Innovation \& Entrepreneurship Competition, E-commerce Innovation, Originality and Entrepreneurship Competition in school. Hold College Students' Survival Challenge for 3 years.

\section{Accumulating a Large Number of Students' Innovation and Entrepreneurship Competition Results and Registering Companies}

Students have achieved excellent results in the innovation and entrepreneurship competition. Since the National College Student "Innovation, Originality and Entrepreneurship" Challenge, the Ministry of Education is held, in the past 6 years, in the first, third, fifth and sixth competition, students respectively have won the grand prize for 3 times and the first prize for twice. Since joining in China Students Service 
Outsourcing Innovation \& Entrepreneurship Competition, in the past 4 years, students respectively have won the second prize for twice and the third prize for 3 times. Since joining in National College Students' Network Business Innovation Application Competition, students respectively have won the first prize for once and the second prize for 3 times. Since joining in China College Student' Entrepreneurship Competition, students have won the silver medal for 3 times and bronze medal for once in Beijing competition area. Form 2 students' innovation and entrepreneurship associations successfully, "Four Wheat Activities Community" and "Youth Club".

Students have registered 3 companies for two years. Based on the accumulation of the event results, students register 3 companies successfully, namely: "Beijing Four Wheat Science Technology and Culture Co. Ltd", "Beijing surf Technology Co. Ltd.", "Beijing Hong Yan Image Culture Media Co. Ltd.".

\section{The Contribution to the Innovation of Ways to Cultivate Innovative and Entrepreneurial Talents}

\section{The Innovation of the Idea of Talent Cultivation}

E-commerce specialty has established the idea of talent cultivation for promoting the training through the events, promoting the learning through the events, and promoting the entrepreneurship through the events. After more than 10 years of professional teaching and practice, achievements are outstanding: students have won the national awards for many times, have started up business successfully and established companies.

\section{The Innovation of the Way of Talent Cultivation}

Based on the new idea established and multi combat platform built, through effective methods, E-commerce specialty forms the way of innovative and entrepreneurial talents cultivation, and communicates and promotes it in the forum of E-commerce specialty construction in Beijing, Tianjin and Hebei Province.

Professional Teaching Guidance Committee participates in the formulation of cultivation project of innovative and entrepreneurial talents, guide professional events and graduation thesis (design).

The establishment of inside-school and outside-school practice bases greatly extends the space to cultivate students' professional ability, and provides rich experience for other specialties' outside-school practice.

The establishment of dual tutorial platform for graduation thesis between college and enterprise and the first implement of dual tutorial system for graduation thesis in the specialty of economics and management, promote the reform and innovation of comprehensive practice of graduation thesis, puts forward to methods and means for application-oriented university applied talents training.

The first establishment of sharing interactive platform for entrepreneurial experience and the successful organizing of E-commerce innovation and entrepreneurship forums open the beginning of sharing and interacting entrepreneurial experience between entrepreneurs and university students.

The establishment of professional events combat platform promotes students to practice through more practical projects, and extends the space of students' innovative and entrepreneurial practice and ability cultivation. 


\section{The Innovation of the Mode and Method of Talent Cultivation}

Focus on the target to cultivate innovative and entrepreneurial talents, and decompose and refine professional curriculum content and incorporate into the relevant courses, through collective discussion; complete ability cultivation, through the process assessment and target assessment, which is the innovation of the mode.

Invite entrepreneurs to the classroom, and complete the curriculum reform through the form of the cooperation between universities and enterprises. Integrate high quality resources and curriculum content of "Introduction to E-commerce", "Internet Marketing", "Project Planning", "E-commerce Security Technology", "E-commerce Website Construction" and "Graduation Design", use methods of project management and competition management, provide students in E-commerce specialty and other specialties the better platform for innovation, originality and entrepreneurship, expand the field of mobile E-commerce, according to students' interests and hobbies, form a number of students innovation and entrepreneurship associations successfully, at the same time, incorporate academic competition and entrepreneurship competition into talent cultivation, promote students' iteration and updating of the knowledge and skills through events, improve the entrepreneurial project, and finally carry out the entrepreneurial work, which is the innovation of the method.

\section{The Promotion and Application of the Innovation of Ways to Cultivate Innovative and Entrepreneurial Talents}

\section{The Significant Improvement of Talent Cultivation Quality}

\section{The Improvement of Students' Professional Practice Ability}

The implementation of dual tutorial system for graduation thesis enhances the ratio of practical problems for thesis/design, improves students' practical application ability, and meets enterprises' actual demand.

$100 \%$ of students have participated in professional practice, students' professional knowledge has been expanded, and professional quality has been enhanced further. Students' summer practice in Neusoft Education in Shenyang in 2016, has obtained the dean and the teacher's praise in Division of Academic Affairs.

The Improvement of Students' Innovative and Entrepreneurial Ability

Students have participated in various events and have won a number of awards, and have conducted results docking with entrepreneurs. In the past five years, students' results are fruitful, in the national professional events, and project teams and corporate investors have carried out results docking.

The students have registered companies successfully. 3 companies have been registered in the past two years.

The Improvement of Students' Employment Ability

The employment rate has remained in the forefront in college and once employment rate has been more than $98 \%$ in the past five years; in all graduates, the number of government civil servants, bank clerks, and employees in the state-owned enterprises has increased, and the number of graduates going abroad increases year by year.

\section{The Specialty's Social Influence}

The effect of talent cultivation is followed up and reported by a number of medium. The effectiveness of talent cultivation has been widely reported by "Baidu Encyclopedia", v.china.com.cn, dahe.cn, ifeng.com, LonTV.com, iqilu.com, Sohu.com, 
www.cqn.com.cn, CCTV.com, China.org.cn, stdaily.com, qianlong.com, Modern Education News and other medium.

Host the 6th National College Student "Innovation, Originality and Entrepreneurship" Challenge Final in Beijing successfully. Invite 10 enterprise and industry experts. 12 teachers from famous universities in Beijing participate in the links of the selection of team works in Beijing division and the final scene reply. The event is focused on and reported by CCTV.com, China.org.cn, stdaily.com, qianlong.com, Modern Education News and other medium.

Host the First Innovation, Originality, Entrepreneurship Forum, Beijing Union University the whole school successfully. The forum is designed to ignite students' innovative and entrepreneurial dreams. The first forum series of activities are divided into five series of activities. Invite 6 enterprise guests, and 8 graduates from information management specialty, E-commerce specialty and Advertising specialty. 4 heads in the college, and a total of 50 teachers participate in the forum.

The results of innovative talents have been communicated and promoted in the forum of E-commerce specialty construction in Beijing, Tianjin and Hebei Province. Expand the popularity and influence of E-commerce specialty in the universities of Beijing.

\section{The Improvement of the Team's Teaching and Research Ability}

Based on the guidance of student's competition and the teaching reform of the curriculum, teachers have won 5 teaching awards. In all kinds of professional events, 8 teachers won the title of excellent guidance teacher. Teachers have been approved 1 project of the Ministry of Education, 1 teaching reform project at municipal level, 4 teaching reform projects at school level and have published 8 education and teaching papers. The number of teachers served as evaluation experts in all kinds of major projects and events are more than 10. Mobile E-Commerce laboratory project was approved by the Ministry of Education. In 2015, the construction of teaching staff - the central 2014 third batch of modern vocational education quality promotion plan -the project of professional construction in teacher cultivation and training system construction and training ( 2 million RMB) was approved. 1 education and teaching reform project in Beijing City was approved in 2015.

\section{Acknowledgement}

This research was financially supported by the project of Construction of Talents' Cultivation Quality: The Construction of Professional Groups in Beijing Universities (PXM2016_014209_000001).

\section{References}

[1] Yu Wendan. Research on "Internet plus" innovative and entrepreneurial talents cultivation of application-oriented undergraduate E-commerce specialty [J]. E-Business Journal, 2015, (12): 73-74.

[2] Yang Nan. "Research on innovative and entrepreneurial talents cultivation mode-Taking E-commerce specialty as an example [J]. E-Business Journal, 2015, (12): 77-78.

[3] Zhao Yu, Research on the Double Tutorial System of graduation thesis of financial management major, Contemporary Education Research and Teaching Practice, 2016, (2): 268 . 
[4] Ge Zhicai, Li Li, Research on the "Dual Tutorial System" guiding mode of economics and management thesis at Independent College, Forward Position, 2013, (23): 133-134.

[5] Sun Yuxia, Zhou Haiyan, Li Xiaoxia, Double tutor of undergraduate graduation theses at medical university, Basic Medical Education, 2014, 16(30): 247-249. 